\title{
Inclusion of informant ratings of cognitive difficulties improves the accuracy of the MMSE in predicting Alzheimer's disease
}

Tierney MC, Herrmann N, Geslani DM, et al. Contribution of informant and patient ratings to the accuracy of the Mini-Mental State Examination in predicting probable Alzheimer's disease. J Am Geriatr Soc 2003;51:813-18.

Is the accuracy of predicting Alzheimer's disease improved by incorporating patient and informant ratings of cognitive difficulties into the Mini-Mental State Examination?

\section{METHODS}

$\square-$ baseline scores.

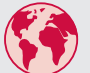

Setting: University teaching hospital, Toronto, Canada; timeframe not specified.

People: 165 people referred by their family physician for suspected memory impairment. People meeting criteria for dementia were excluded.

Test: Mini-Menal State Examination (MMSE), taken at enrolment IUU] and at 2 years follow up.

Diagnostic standard: 19 item rating scale from section $\mathrm{H}$ of the Cambridge Mental Disorders Examination (CAMDEX), taken at enrolment and at 2 years follow up. Section $\mathrm{H}$ of the CAMDEX was administered to both the subject and a nominated informant (a person with whom the subject was most familiar), to determin both the subject's and informant's perceptions of the subject's cognitive functioning difficulties.

Outcomes: Diagnosis of probable Alzheimer's disease: sensitivity and specificity of tests.
Table Sensitivity, specificity, positive and negative likelihood ratios for individual tests and combination of tests.

\begin{tabular}{|c|c|c|c|c|}
\hline & MMSE & $\begin{array}{l}\text { Patient } \\
\text { CAMDEX }\end{array}$ & $\begin{array}{l}\text { Informant } \\
\text { CAMDEX }\end{array}$ & $\begin{array}{l}\text { Combined } \\
\text { CAMDEX and } \\
\text { MMSE }\end{array}$ \\
\hline $\begin{array}{l}\text { Sensitivity \% } \\
\text { (95\% Cl) } \\
\text { Specificity \% } \\
\text { (95\% CI) } \\
\text { Positive } \\
\text { likelihood } \\
\text { ratio (95\% Cl) }\end{array}$ & $\begin{array}{l}69 \\
(49 \text { to } 84) \\
78 \\
(68 \text { to } 86) \\
3.12(1.99 \\
\text { to } 4.89)\end{array}$ & $\begin{array}{l}66 \\
\text { (46 to } 81) \\
59 \\
\text { (48 to } 69) \\
1.60(1.12 \\
\text { to } 2.28 \text { ) }\end{array}$ & $\begin{array}{l}90 \\
(71 \text { to } 97) \\
73 \\
(62 \text { to } 81) \\
3.28(2.31 \\
\text { to } 4.65)\end{array}$ & $\begin{array}{l}83 \\
(63 \text { to } 93) \\
79 \\
(69 \text { to } 86) \\
3.93(2.57 \\
\text { to } 6.00)\end{array}$ \\
\hline $\begin{array}{l}\text { Negative } \\
\text { likelihood } \\
\text { ratio ( } 95 \% \mathrm{Cl})\end{array}$ & $\begin{array}{l}0.40(0.23 \\
\text { to } 0.69)\end{array}$ & $\begin{array}{l}0.58(0.35 \\
\text { to } 0.99)\end{array}$ & $\begin{array}{l}0.14(0.05 \\
\text { to } 0.42)\end{array}$ & $\begin{array}{l}0.22(0.10 \\
\text { to } 0.49)\end{array}$ \\
\hline
\end{tabular}
and Women's College Health Sciences Center, University of Toronto, 2075 Bayview Avenue, Toronto, Ontario, Canada; mary.tierney@sw.ca Source of funding: The Ontario Ministry of Health, Toronto, Ontario, Canada.

\section{MAIN RESULTS}

After 2 years, 29 people developed probable Alzheimer's disease. There was a significant difference in MMSE results and informant CAMDEX results between those people with Alzheimer's disease and those not developing Alzheimer's disease $(\mathrm{p}<0.001$ for both scores). There was no significant difference in patient CAMDEX results between people with and without Alzheimer's $(\mathrm{p}=0.865)$. Sensitivity and specificity of tests are presented in the table.

\section{CONCLUSIONS}

Inclusion of informant ratings of cognitive difficulties significantly improves the accuracy of the MMSE for prediction of probable Alzheimer's disease.

Commentary

C ne of the most important advances in clinical research on Alzheimer's disease (AD) during the past decade is the identification of cognitive changes that occur during a so-called "preclinical" phase that precedes the manifestation of the overt dementia syndrome. ${ }^{1}$ The discovery of these potential cognitive markers is expected to push back the point at which $A D$ can be reliably detected. The very early detection of $A D$ is extremely important now that new treatments that might delay the disease's progression are on the horizon. ${ }^{2}$

To date, most markers of imminent dementia are measures of performance on objective tests of learning and memory that require relatively lengthy administration procedures and specialised training to interpret. ${ }^{3}{ }^{4}$ This limits their usefulness in primary practice settings where the time and expertise necessary to implement them is often lacking. Tierney and colleagues provide an alternative approach to the prediction of impending dementia based upon procedures that are frequently part of a usual primary work-up for elderly patients with suspected memory dysfunction. These investigators showed high predictive accuracy using aspects of the brief, widely used MMSE, an informant's report of the patient's cognitive decline, and the patient's own report of his or her condition. The clinical utility of this approach is quite high given that the required information is typically acquired in standard practice, and that the investigators provide a website that calculates a patient's probability of developing dementia within the next two years, based on logistic regression coefficients for the measures. The method can provide the clinician with important knowledge that might influence decisions about referral for further testing or implementation of treatment. Caution must be exercised, however, as the generaliseability of this approach to an independent sample of patients has not yet been shown, and regression based prediction of outcome for a single patient from group data can be precarious.

David P Salmon, PhD Professor of Neurosciences, University of California, San Diego, CA, USA

1 Collie A Maruff P. The neuropsychology of preclinical Alzheimer's disease and mild cognitive impairment. Neurosci Biobehav Rev 2000;24:365-74.

2 Grundman M, Thal $\mathrm{L}$. Treatment of Alzheimer's disease. Neurol Clin 2000;18:807-27.

3 Albert MS, Moss MB, Tanzi R, et al. Preclinical prediction of AD using neuropsychological tests. J Int Neuropsychol Soc 2001;7:631-9.

4 Bondi MW, Salmon DP, Galasko D, et al. Neuropsychological function and apolipoprotein E genotype in the preclinical detection of Alzheimer's disease. Psychol Aging 1999;14:295-303. 